Annuaire suisse de politique de développement

$14 \mid 1995$

Annuaire Suisse - Tiers Monde 1995

\title{
Principales abréviations
}

\section{(2) OpenEdition}

1 Journals

Édition électronique

URL : http://journals.openedition.org/aspd/1494

DOI : 10.4000/aspd.1494

ISSN : 1663-9669

Éditeur

Institut de hautes études internationales et du développement

\section{Édition imprimée}

Date de publication : 1 février 1995

Pagination : 331-333

ISSN : 1660-5934

\section{Référence électronique}

"Principales abréviations », Annuaire suisse de politique de développement [En ligne], 14 | 1995, mis en ligne le 04 mai 2013, consulté le 08 septembre 2020. URL : http://journals.openedition.org/aspd/1494 ; DOI : https://doi.org/10.4000/aspd.1494 


\section{PRINCIPALES ABREVIATIONS}

ACP Afrique, Caraïbes, Pacifique

AELE Association européenne de libre-échange

Al Amnesty international

AID Agence internationale pour le développement (IDA)

ALENA Accord de libre-échange nord-américain

AMF Arrangement multifibre

AMGI Agence multilatérale de garantie des risques à l'investissement

APD Aide publique au développement

ASEAN Association des pays du Sud-Est asiatique

BAD Banque africaine du développement

BCSD Business Council for Sustainable Development

BERD Banque européenne de la reconstruction et du développement

BID Banque interaméricaine du développement

BIT Bureau international du travail

BNS Banque nationale suisse

BRI Banque des règlements internationaux

CAD Comité d'aide au développement de l'OCDE

CDD Commission du développement durable

CE Communautés européennes ou Communauté économique

CEI Communauté des Etats indépendants

CEPAL Commission économique des Nations Unies pour l'Amérique latine

CICR Comité international de la Croix-Rouge

CIN Comité intergouvernemental des négociations

CNUCED Conférence des Nations Unies sur le commerce et le développement

CNUED Conférence des Nations Unies pour l'environnement et le développement

DAR Délégué aux réfugiés

DDA Direction de la coopération au développement et de l'aide humanitaire (Département fédéral des affaires étrangères)

DFAE Département fédéral des affaires étrangères

DFEP Département fédéral de l'économie publique

DFJP Département fédéral de justice et police

DMF Département militaire fédéral

DTS Droits de tirage spéciaux

ECOSOL Conseil économique et social des Nations Unies

EPFZ École polytechnique fédérale de Zurich

FAO Organisation des Nations Unies pour l'alimentation et l'agriculture

FASE Facilité d'ajustement structurel élargie

FASR Facilité d'ajustement structurel renforcée

FEM Fonds pour l'environnement mondial (GEF, Global Environment Facility) 
FF Feuille fédérale

FMI Fonds monétaire international

FNRS Fonds national de recherche scientifique

G7 Groupe des 7 pays les plus industrialisés

GAFI Groupe d'action financière sur le blanchiment de capitaux

GATT Accord général sur les tarifs douaniers et le commerce

GIEC Groupe d'experts intergouvernemental sur l'évolution du climat (IPCC)

GRE Garantie contre les risques à l'exportation

HCR Haut commissariat aux réfugiés

i3m Information Tiers Monde/ InfoSud

IDH Indicateur du développement humain

LMIC Lower Middle Income Countries

MIC Middle Income Countries, Pays à revenue intermédiaire

MODS Mouvement pour une Suisse ouverte, démocratique et solidaire

NPI Nouveau pays industrialisés

NPSA Nouveau Programme substantiel d'action pour les années 80 en faveur des Pays les moins avancés

NZZ Neue Zürcher Zeitung

OCDE Organisation de coopération et de développement économiques

OFAEE Office fédéral des affaires économiques extérieures (Département de l'économie publique)

OFEFP Office fédéral de l'environnement, de la forêt et du paysage

OFS Office fédéral de la statistique

OIBT Organisation internationale des bois tropicaux

OIC Organisation internationale du café

OIT Organisation internationale du travail

OMC Organisation multilatérale de commerce

OMM Organisation météorologique mondiale

OMPI Organisation mondiale de la propriété intellectuelle

OMS Organisation mondiale de la santé

ONG Organisations non-gouvernementales

OSEO Oeuvre suisse d'entraide ouvrière

PDC Parti démocrate chrétien

PIB Produit intérieur brut

PMA Pays les moins avancés

PNB Produit national brut

PNR Programme National de recherches

PNUD Programme des Nations Unies pour le développement

PNUE Programme des Nations Unies pour l'environnement

PRD Parti radical démocratique suisse

PS Parti socialiste

PVD Pays en développement

SFI Société financière internationale

SGP Système généralisé des préférences 
SIPRI Institut International de recherche sur la paix (Stockholm International Peace Research Institute)

SPE Société suisse pour la protection de l'environnement

STF Aide à la transition systémique (Systemic transformation facility)

UBS Union de banques suisses

UDC Union démocratique du centre

UE Union européenne

UNESCO Organisation des Nations Unies pour l'éducation, la science et la culture

UPOV Union internationale pour la protection des obtentions végétales

WWF World Wildlife Fund 